\title{
Interannual variability, global teleconnection, and potential predictability associated with the Asian Summer Monsoon
}

\author{
K. M. Lau, K. M. Kim \\ Climate and Radiation Branch \\ NASA/Goddard Space Flight Center \\ Greenbelt, MD 20771 \\ and \\ J. Y. Li \\ Department of Atmospheric Sciences \\ Seoul National University \\ Seoul, Korea
}

October, 2001

(Submitted as a book Chapter on East Asian Monsoon, World Scientific Publication) 


\title{
Interannual Variability, Global Teleconnection, and Potential Predictability Associated with the Asian Summer Monsoon
}

\author{
K. M. Lau ${ }^{1}$, K. M. Kim ${ }^{2}$, and J. Y. $\mathrm{Li}^{3}$ \\ Submitted as a book Chapter on East Asian Monsoon \\ World Scientific Publication
}

\section{Popular Summary}

Floods and droughts associated with the Asian summer monsoon (ASM) are among the most devastating natural disasters affecting human society. Year-to-year fluctuations of the Asian monsoon affect not only Asian countries but also the rest of the world through "teleconnection". Teleconnection is the linkage between weather and climate phenomena in geographic regions separated by vast distances, manifested as signals in the large-scale atmospheric circulation, temperature, air pressure, sea surface temperature, and ocean circulation. Better understanding of the physics of teleconnection may help in improving climate predictions.

In this paper, the teleconnections between summertime precipitation anomalies over East Asia and over North America are examined. Two teleconnection modes linking ASM variability to summertime precipitation over the continental North America were identified. These modes link regional circulation and precipitation anomalies over East Asia and continental North America, via coupled atmosphere-ocean variations over the North Pacific. The first mode (Mode-1) has a large zonally symmetric component in the atmosphere, which are associated with subtropical jetstream variability. Because a wavetrain pattern links centers of precipitation anomalies of the same sign over Japan and the US Midwest, Mode-1 has been dubbed the "Tokyo-Chicago Express". The second mode depicts a wavetrain with wavenumber 6, spanning East Asia, the North Pacific and North America. It affects rainfall over central East Asia and the central US, earning it the nickname: "The Shanghai-Kansas Express". Both modes possess strong SST expressions in the North Pacific. The twoteleconnection modes may be derived from intrinsic modes of sea surface temperature variability in the extratropical oceans, which are forced in part by atmospheric variability and in part by air-sea interactions.

The potential predictability of the ASM associated with SST variability in different ocean basins is explored using a new canonical ensemble correlation (CEC) prediction scheme. It is found that SST anomalies in tropical Pacific, i.e., El Niño, is the most dominant forcing for the ASM, especially over the maritime continent and eastern Australia. SST anomalies in the Indian Ocean may trump the influence from El Niño in western Australia and western maritime continent. Both El Niño and North Pacific SSTs contribute to monsoon precipitation anomalies over Japan, southern Korea, and northern and central China. By optimizing SST variability signals from the world ocean basins using CEC, the overall predictability of ASM can be substantially improved.

${ }^{1}$ NASA/Goddard Space Flight Center

${ }^{2}$ Science Systems and Applications, INC.

${ }^{3}$ Seoul National University 


\begin{abstract}
In this Chapter, aspects of global teleconnections associated with the interannual variability of the Asian summer monsoon (ASM) are discussed. The basic differences in the basic dynamics of the South Asian Monsoon and the East Asian monsoon, and their implications on global linkages are discussed. Two teleconnection modes linking ASM variability to summertime precipitation over the continental North America were identified. These modes link regional circulation and precipitation anomalies over East Asia and continental North America, via coupled atmosphere-ocean variations over the North Pacific. The first mode has a large zonally symmetry component and appears to be associated with subtropical jetstream variability and the second mode with Rossby wave dispersion. Both modes possess strong SST expressions in the North Pacific. Results show that the two teleconnection modes may have its origin in intrinsic modes of sea surface temperature variability in the extratropical oceans, which are forced in part by atmospheric variability and in part by air-sea interaction.

The potential predictability of the ASM associated with SST variability in different ocean basins is explored using a new canonical ensemble correlation prediction scheme. It is found that SST anomalies in tropical Pacific, i.e., El Niño, is the most dominant forcing for the ASM, especially over the maritime continent and eastern Australia. SST anomalies in the India Ocean may trump the influence from El Niño in western Australia and western maritime continent. Both El Niño and North Pacific SSTs contribute to monsoon precipitation anomalies over Japan, southern Korea, northern and central China. By optimizing SST variability signals from the world ocean basins using CEC, the overall predictability of ASM can be substantially improved.
\end{abstract}




\section{Introduction}

Floods and droughts caused by variability of the Asian summer monsoon (ASM) are among the most devastating of natural disasters which impact a large segment of the world population. ASM floods and droughts are extremely variable in space and time. During the summer of 1998, the great flood over the Yangtze River caused a record 3700 deaths, 223 million people displaced and up to 30 billion US dollars in crop losses and property damages. In the same year, excessive monsoon rainfall also caused severe flooding over Bangladesh displacing 30 million people and wrecking up losses and property damages to over 3 billion US dollars. Yet, one year before, in the summer of 1997, the above regions had nearly normal summer rainfall, while northern China had been stricken with a record drought which began since the early 1990's. During the same year, southern China was gripped by wide spread flooding, but the averaged rainfall over the entire India subcontinent was nearly normal.

Because of the possibility of mitigating the adverse socio-economic impacts caused by ASM anomalies, understanding and predicting ASM monsoon variability is paramount. Recent studies have shown that the large variability within the ASM may be related to the intrinsic variability, such as intraseasonal oscillations (ISO), tropospheric biennial oscillation (TBO), sea surface temperature anomalies in the Indo-Pacific region, and their interactions with the El Niño Southern Oscillation (ENSO) (Lau and Wu 2001; Lau and Nath 2000; Meehl and Arblaster 1998; Shen and Kimoto 1999; Meehl 1997; Ju and Slingo 1995 and many others). Lau and $\mathrm{Wu}(1999,2001)$ found that both regional and basin-scale processes contributed significantly to the observed ASM rainfall anomalies in 1997 and 1998. Lau et al. (2000) demonstrated that, based on the regional 
characteristics of dynamics and lower boundary forcings, at least two major subcomponents of the ASM, i.e., the South Asia monsoon and the East-Asia monsoon need to be distinguished. These two components, while connected to each other, may interact differently with ENSO and other global climate phenomena, e.g., the North Atlantic Oscillation, decadal-to-interdecadal variability and global change, to yield very different responses to global scale forcings (Kumar et al. 1999; Chang et al 2001).

There are now growing evidence that not only is the ASM affected by global scale forcings, the ASM itself can influence global climate (Yasunari and Seki 1992). Kirtman and Shukla (2000) and Chung and Nigam (2000) found that momentum and heat fluxes associated with anomalies of the ASM may increase the variability of ENSO cycles. Kim and Lau (2000) demonstrated that the 6-month time lag between ASM surface wind forcings and peak SST in the tropical eastern Pacific may induce biennial tendency in ENSO cycles. Hoerlings et al (2000) showed that decadal climate change signals in the North Atlantic may have their roots in tropical convection in the IndoPacific regions. Teleconnection arising from monsoon processes on seasonal to interannual time scales have been explored in previous studies. Nitta (1987) and Huang and Sun (1992) showed that summertime convection in the vicinity of the northern South China Sea and the Philippines may excite Rossby wavetrain that span the North Pacific to North America. Lau (1992) and Lau and Peng (1992) suggested that similar wavetrain signal may stem from instability of the summertime large-scale basic flow, and hence may not be sensitive to the exact location of the forcing. More recently, Lau and Weng (2000a, b) have shown evidence that summertime rainfall anomalies over the East Asian continent and North America may be linked by teleconnection patterns, with pronounced 
SST signals in the extratropical Pacific. Ting and Wang (1997) noted that North America summertime rainfall anomalies may be correlated with extratropical Pacific SST. However, it is not clear whether the teleconnection patterns are derived from variability of the atmosphere alone or are component of intrinsic coupled atmosphere-ocean system in the extratropics. If the latter is true, it is possible that extratropical SST, in addition to tropical SST may have implication on predictability of the ASM.

In this Chapter, we focus on the discussion of the climate teleconnection associated with the ASM and implications on its potential predictability. Aspects of the interannual variability of the ASM including effects of intraseasonal oscillations, tropospheric biennial oscillations, and ENSO are covered in other Chapters of this book. In Section 2, we review the basic structures of the two basic components of the ASM, i.e., the South Asian Monsoon (SAM) and the East Asian Monsoon (EAM). In Section 3, we discuss the boreal summer teleconnection patterns associated with monsoon variability and with North America summertime precipitation anomalies. In Section 4, we show results demonstrating that the teleconnection patterns are manifestations of intrinsic, recurrent summertime SST modes in the extratropical oceans which are distinct from ENSO. In Section 5, we assess the potential predictability of the ASM, and its sources associated with SST variability in different ocean basins. Concluding remarks are presented in Section 6 .

\section{Interannual variability of the ASM}

The interannual variability of the ASM encompasses a complex mix of regional and sub-regional scale characteristics. To better define monsoon regionality and ENSO impacts, a number of ASM regional indices have been proposed by different authors 
(Goswami et al. 1999; Wang and Fan 1999; Lau et al. 2000; Wang et al. 2001). Lau et al (2000) defined two indices RM1 and RM2, respectively for the South Asian Monsoon (SAM) and the East Asian Monsoon (EAM). RM1 is a measure of the vertical shear of the meridional wind over the longitude sector of the Indian subcontinent including the Bay of Bengal. RM2 is measure of the lateral displacement of the East Asian jetstream, represented as the zonal wind gradient between the midlatitude and the subtropics:

$$
\begin{aligned}
\mathrm{RM} 1= & \left(\mathrm{v}_{850 \mathrm{mb}}-\mathrm{v}_{200 \mathrm{mb}}\right) \\
& \text { over the region }\left[10^{\circ} \mathrm{N}-35^{\circ} \mathrm{N}, 70^{\circ} \mathrm{E}-110^{\circ} \mathrm{E},\right] \\
\mathrm{RM} 2= & \left(\mathrm{u}_{200 \mathrm{mb}}\left[40^{\circ} \mathrm{N}-50^{\circ} \mathrm{N}, 110^{\circ} \mathrm{E}-150^{\circ} \mathrm{E}\right]\right. \\
& \left.-\mathrm{u}_{200 \mathrm{mb}}\left[25^{\circ} \mathrm{N}-35^{\circ} \mathrm{N}, 110^{\circ}-150^{\circ} \mathrm{E}\right]\right)
\end{aligned}
$$

where the zonal and meridional winds are averaged over the geographic regions indicated. It should be pointed out that while these two indices bring out salient features separating the SAM and EAM especially with respect to teleconnection, the results are largely independent of the indices used, as far as separating the two components of the ASM. Similar patterns can be obtained from EOF or combined EOF analyses (not shown) or by using other indices (e.g. Wang et al 2001).

\section{a. SAM variability}

The patterns shown in Figs. 1 and 2 are regressions of RM1 and RM2 based on CMAP monthly rainfall and NCEP reanalysis wind. Fig. 1a depicts a classic monsoonal inverse relationship in rainfall between land and ocean, associated the interannual variability of SAM. Regions of largest positive rainfall anomalies are found over land and coastal regions of South Asia, including the Indian subcontinent, the Bay of Bengal, northern Indo-China and southern East Asia. Negative rainfall anomalies are found in the surrounding oceanic areas. The strongest negative anomalies are found over the 
southeastern Indian Ocean, the South China Sea, and the subtropical and tropical western Pacific. Associated with the positive rainfall anomalies are strong low-level westerly and southwesterly flows over the Arabian Sea and the Bay of Bengal (Fig. 1b). This circulation pattern suggests an enhancement of the climatological ASM circulation. Two branches of cross-equatorial flow can be identified: one located along the east coast of Africa and a second one emerging from southeastern Indian Ocean. The latter appears to be the main supply of the low-level inflow into the Bay of Bengal. Another regional of strong meridional flow is found around $110^{\circ} \mathrm{E}$, from southern to northern East Asia, associated with a low-level anticyclone over the East China Sea. This anticyclone represents an enhancement and westward extension of the West Pacific Subtropical High, which is associated with surface easterlies and subsidence over the South China Sea region. At the upper level, a prominent anticyclone center, identified as the South Asia High, is found to the northwest of the positive heating (Fig. lc). The circulation pattern is also consistent with induced Rossby-type circulation by latent heating located off the equator (Gill 1980, Lau and Lím 1982). Further downstream, an upper level anticyclone is found over northern Korea (near $40^{\circ} \mathrm{N}, 120^{\circ} \mathrm{E}$ ). Recent results have shown that interannual variability of the SAM is influenced directly by the shift of the Walker circulation during an El Niño. Land regions in SAM particularly are sensitive to the local overturnings induced by the shift of the Walker circulation (Anamalai and Slingo 1999, Ju and Slingo 1995, Lau and Nath 2000). The local overturnings are themselves affected by the strong intraseasonal variability in SAM. Thus the regional consistency of the responses of SAM to large scale SST forcings is not very high from year to year (Lau and $\mathrm{Wu} 2000$ ). 


\section{b. EAM variability}

In contrast to RM1, the precipitation pattern for RM2 in Fig. 2 shows well-defined zonaly oriented structure, indicating alternating dry and wet belts over the subtropical western Pacific and East Asia sector, with only weak signal over the Indian subcontinent. The meridional extent of the monsoon-related rainfall anomalies is very large, covering regions from the equator to $50^{\circ} \mathrm{N}$. In Fig. $2 \mathrm{~b}$, the low level circulation field indicates a strong influence from the West Pacific Subtropical High (WPSH). When convection is strongly developed over Southeast Asia/South China Sea region, low level westerly flow prevails from the southern Bay of Bengal to the western Pacific, across Indochina and central South China Sea. The circulation pattern signals a northward advance of the WPSH over East Asia. The easterly inflow near $25-30^{\circ} \mathrm{N}$ is associated with local sinking motion and the returning westerly flow is linked to rising motion near $35-45^{\circ} \mathrm{N}$ (not shown). At $200 \mathrm{hPa}$ (Fig.2c), the most prominent feature is the presence of an intensive anticyclone over East Asia, associated with the meridional shift of the axis of the climatological subtropical jet in response to tropical heating in the Southeast Asia region (Lau et al. 2000). The East Asian anticyclone is connected upstream to an anomalous anticyclone associated with the South Asian High.. Because the East Asian jetstream is controlled by extratropical dynamics as much as by tropical heating, the EAM has been called a "hybrid " monsoon system. As shown in Lau et al. (2000), the interannual variability of EAM is closely tied to intrinsic SST variations in the subtropical and extratropical North Pacific, more than to those in the tropical eastern Pacific. Given the weak, and somewhat inconsistent response of EAM to ENSO, it is possible that the EAM anomalies may be strongly influenced by the presence of intrinsic 
climate modes involving the West Pacific Subtropical High, the subtropical jetstream and related air-sea interaction in the extratropical oceans. This possibility is further explored in Sections 3 and 4.

\section{Teleconnection Dynamics}

Analysis of the vorticity balance in the RM1 region shows an approximate cancellation between the meridional advection of planetary scale vorticity and generation by the divergence of the anomalous flow, suggesting that the vorticity balance of the SAM is of the classic Sverdrup-type i.e.,

$$
\beta v^{\prime}+(\bar{\zeta}+f) \nabla \cdot \mathbf{V}^{\prime} \approx 0
$$

A similar analysis shows that the dominant balance for the EAM in the RM2 region, $\left(30-40^{\circ} \mathrm{N}\right)$ is between the vorticity generation induced by divergence and the advection of the anomalous vorticity by the mean circulation, i.e.,

$$
(\bar{\zeta}+f) \nabla \cdot \mathbf{V}^{\prime}+\overline{\mathbf{V}} \bullet \nabla \zeta^{\prime}=0
$$

As shown in the following discussions, the fundamental difference in the vorticity balance between SAM and EAM has important implication on the dynamics of teleconnection patterns generated by SAM and EAM respectively.

a. ASM teleconnection

Figure $3 \mathrm{a}$ and $3 \mathrm{~b}$ show the correlation maps of the northern hemisphere $300 \mathrm{hPa}$ geopotential field with RM1 and RM2 respectively. Areas with correlation coefficients equal to or exceeding the $95 \%$ significance level are shaded. For RMI (Fig. 3a), the anticyclone over northwestern India due to heating over South Asia appears as a part of 
an elongated ridge system extending from northern Africa. The South Asia anticyclone is linked to a high over northeastern Asia. As discussed previously, this high is associated with the fluctuation of the WPSH. The teleconnection pattern associated with RM2 is broadly similar to that of RM1, but much stronger and more well-defined with a strong zonally oriented trough/ridge system spanning the coastal region of East Asia, Japan, and the north central Pacific (Fig. 3b). This system is connected to the north-south migration of the subtropical jetstream associated with anomalous heating over the South China Sea and western Pacific region (See Fig. 2a). The similarities between the RM1 and RM2 teleconnection patterns in the Asian and western Pacfic sectors indicate that the northward shift of the jetstream and the fluctuation of the West Pacific High may be tied to the development of the South Asia High, with enhanced heating over the South Asian land regions (see Fig. 1a). Note that the wavetrain appears to extend over North America, downstream of the north Pacific anomalies. The result that similar downstream teleconnection signals are excited independent of the sources suggests that the teleconnection pattern may be manifestation of intrinsic unsable modes in the northern summer basic state flow (Lau and Peng 1992). The RM2 teleconnection pattern is also similar to the Pacific-Japan pattern associated with tropical heating near the Philippines and zonally banded convective pattern over the subtropical western Pacific reported by Nitta (1987). As we show in the next subsection, teleconnection pattern similar to those shown in Fig. 3 can also be recovered based on North America precipitation anomalies. The results are consistent with the vocticity balance of $\mathrm{Eq}(4)$ which suggests that the basic state vorticity gradient associated with the East Asia jetstream is a major source of vorticity and that the teleconnection pattern is more strongly controlled by the media in 
which the planetary waves propagate or grow, than energy dispersion from the specific location of the heat source.

\section{b. North America teleconnection}

In this subsection we present results of possible teleconnection linking East Asian monsoon variability to North America summertime rainfall anomalies. Teleconnection between North America summertime climate and ASM variability may arise not only from direct ASM influence but also from the fact that both system are simultaneously under the control of the same global scale forcings, e.g. El Niño, the Pacific Decadal Oscillation or the Arctic Oscillation. Hence understanding of the teleconnection between climate anomalies in Asia and in North America may shed new light on the mechanism and predictability of summertime climate fluctuations for both continents.

Two characteristic patterns linking US summer precipitation to large scale circulation and SST anomalies have been identified (cf. Lau and Weng $2000 \mathrm{a}, \mathrm{b}$ ). Figures 4 shows the patterns of 850 -hPa wind, rainfall and SST associated with the most dominant mode (Mode-1) based on a Singular Value Decomposition of the US rainfall and $500 \mathrm{hPa}$ geopotential variability. Mode- 1 explains $35 \%$ of the co-variability between US rainfall and $500 \mathrm{hPa}$ geopotential height. Its principal component (not shown) projects strongly on the severe flood over the US Midwest in 1993. Mode-1 depicts a zonally oriented Pan-Pacific pattern rainfall/circulation stretching from East Asia/Japan region to North America (Fig.4a). Excessive rainfall is found over the northern and northwestern North America and deficient rainfall over the eastern and southeastern U. S. The rainfall pattern is coupled to an anomalous low-level anticyclonic flow over the eastern US, which favors the transport of warm moist air from the Gulf coast to the US 
Midwest. Along the equator, there is a weaker signal indicating generally enhanced rainfall in a large fetch of enhanced westerlies in the central and eastern equatorial Pacific. The zonally oriented rainfall and circulation patterns over the Asian-West Pacific sector is quite similar to that associated with EAM as shown in Fig. 2a. The pattern links rainfall anomalies of the same sign over Japan, western Canada and the US Midwest, and has been referred to as the "Tokyo-Chicago Express".

The regressed SST anomaly pattern for Mode 1 suggests possible El Niño influence, as evidenced in the positive SST over the equatorial eastern and central Pacific (Fig 4b). However, the dominant feature here is an extensive cold tongue in the extratropical Pacific (near $40^{\circ} \mathrm{N}$ ), stretching from the sea of Japan to the west coast of North America. This cold SST anomaly appears to underlie the anomalous low-level cyclonic circulation and rainfall anomalies over the North Pacific (Fig.4a). Increased cyclonic activities imply stronger surface wind, and cloudy and rainy conditions, leading to the cooling of the upper ocean by evaporation and by shortwave cloud shielding. Hence, the result suggests that the SST anomalies in the extratropics may arise from forcings of the extratropical ocean by atmospheric wind that have been shown to operate during boreal winter (Lau and Nath, 1996, 2001). Here, we suggest that coupled air-sea interaction my also play a critical role in sustaining and/or amplifying the atmospheric and oceanic anomalies.

Mode- 2 explains $30 \%$ of the covariability between US rainfall and global geopotential height. The associated $850-\mathrm{hPa}$ wind and rainfall patterns suggest that US summer time rainfall variability may be associated with monsoon rainfall variability over Indo-China and the tropical western Pacific region (Figs. 5a). The principal component 
(not shown) of this mode shows a strong projection on the severe drought over the US in the summer of 1998. Excessive rainfall is found over the west coast of Canada and below normal rainfall over central US. The associated low-level flow indicates a large anticyclone over northeastern North America coupled to a cyclone over the Gulf region. This anticyclone/cyclone couplet induces anomalous low-level easterlies in southern U.S., effectively cutting off moisture supply from the Gulf of Mexico, leading to reduced rainfall condition over the central US. The wave pattern over North America appears to be a part of a much larger and well-organized wavetrain emanating from the subtropical western Pacific, in an arc across the north Pacific to North America. Regions of enhanced (reduced) rainfall appear to align along the direction of the wavetrain, coinciding with low-level cyclonic (anticyclonic) circulation that can be traced back to enhanced convection over Indo-China. The anticyclone over the subtropical western Pacific near the Philippine has been identified as one of the key features of the Asian summer monsoon variability affecting droughts and floods in China, Japan and Korea (Lau and Wu 2001, Wang et al. 2001). The Mode-2 teleconnection has been referred to as the "Shanghai-Kansa Express" as they affect rainfall variability of the two regions.

Mode-2 is associated with well-defined extratropical SST anomalies, with positive (negative) SST anomalies underlying the anticyclones (cyclones) (Fig. 5b). Again, the displacement of the circulation pattern with respect to the SST again suggests that the SST anomalies may be forced by local atmospheric circulation. However, the large-scale SST gradient so generated is likely to provide a strong feedback to the overlying atmosphere. There is only a weak SST signal in the tropical eastern Pacific. Hence, this 
mode appears to be independent of El Niño/La Niña, but more closely related to variability of the Asian/West Pacific monsoon convection.

\section{c. Global Linkages}

To confirm that the teleconnection patterns shown in Figs 4 and 5 are truly global, Fig. 6 shows the regression of the Mode-1 PC against the global $500 \mathrm{hPa}$ geopotential and $850 \mathrm{hPa}$ wind and $200 \mathrm{hPa}$ velocity potential. For Mode-1 (Fig.6a), the "TokyoChicago Express" emerges a distinct feature in the 500hPa field, embedded in a global pattern that include signals over western Europe possibly connecting with the Atlantic region via the polar regions. The $850 \mathrm{hPa}$ wind anomaly is consistent with the $500 \mathrm{hPa}$ height anomaly, indicating quasi-geostrophic flow, with deep vertical structure at least up to the mid-troposphere. Figure 6a strongly suggests that the regional circulation over the US is a part of a global pattern associated with extratropical stationary waves and jetstream variability along latitude belts between $30^{\circ}-60^{\circ} \mathrm{N}$. Mode- 1 also features strong low-level wind signal in the equatorial central Pacific and the maritime continent. The $200 \mathrm{hPa}$ velocity potential regression (Fig. $8 \mathrm{~b}$ ) suggests that Mode-1 may be related to the fluctuation of the Walker circulations, driven by heat sources and sinks in the western Pacific/maritime continent, and the Mexican monsoons. The divergent circulation associated with these overturning cells may cause through vorticity advection, the midlatitude jetstream to accelerate or decelerate, effectively providing a source of vorticity for downstream wave development (Sardesmuckh and Hoskins 1988, and Lau and Peng 1992). Large scale coherent signals are also found over the Southern Hemisphere extratropics, which experiences the austral winter during JJA.

The Mode- 2 regression pattern suggests that the "Shanghai-Kansas Express" shown in Fig. 7a is clearly a part of a circum-global Rossby wave pattern, spaning the northern 
extratropics (Fig. 7a). A major apparent heat source is evidence in the divergent center in the Indian Ocean in Fig. 7b. Elsewhere, the upper level divergent and convergent patterns are consistent with the wavetrain signal shown in Fig. 7a. The overall velocity potential pattern suggests that in addition to heat sources of the Indo-Pacific monsoon, those associated with the South Pacific Convergence Zone, the northwestern Pacific and the eastern equatorial Pacific may be important in forcing the Mode-2 response.

\section{Extratropical climate modes}

The strong coherent SST signals in the North Pacific, and global linkages associated with the teleconnection patterns suggest that they may stem from summertime intrinsic SST modes in the subtropical and extratropical oceans, distinct from ENSO. This notion is confirmed in Figs. 8a and b, which show the first two EOF modes of SST interannual variability of the North Pacific and North Atlantic $\left(>20^{\circ} \mathrm{N}\right)$ during JuneAugust. Analyses using only North Pacific SST or only North Atlantic SST yield similar results. It is clear that the SST patterns associated with the first and second SST modes have strong similarities in the North Pacific to that associated with Mode-1 and Mode-2 respectively (See Figs. $4 \mathrm{~b}$ and $5 \mathrm{~b}$ ). In addition, in the first extratropical EOF mode (ESST1), the North Pacific SST varies coherently with that over the North Atlantic, having anomalies of the same sign, centered at $40^{\circ} \mathrm{N}$. The structures of second mode (ESST2) in the two oceans are also similar and have the same polarity (Fig.8b). This coherence in oceanic signals suggest the underpinning of an "atmospheric bridge" linking the two ocean basins (cf. Lau and Nath 1996).

The lagged correlation analysis of the principal components of ESST1 and ESST2 with Niño 3.4 SST is shown in Fig. 9. ESST1 is correlated with Niño 3.4 SST (>95\% 
confidence level) for the current and previous seasons. Yet it is not significantly correlated with Niño 3.4 SST in the previous or following winters, when the El Niño signals are strongest. The lagged correlation SST spatial patterns associated with Mode-1 (not shown) are distinctly different from the evolution of El Niño. For ESST2, no significant correlation with Niño 3.4 SST exists at any lag. Hence it may be concluded that both extratropical SST modes are distinct from El Niño.

Composite analyses with respect to the positive and negative phases of the ESST1 and ESST2 yield teleconnection patterns in $850 \mathrm{hPa}$ wind and 500hPa geopotential (Fig. 10 and 11) that are similar to Mode- 1 and Mode- 2 . The zonally oriented structures in the North Pacific in the ESST1 composite is quite similar to the "Tokyo-Chicago Express" pattern shown in Figs 4 and 6. The simultaneous occurrence of low level anticyclones in the northwestern Pacific and the Atlantic over regions of warm SST is the most distinct feature (Fig. 10a). Here, one gets the impression that the Pacific signal is a part of global pattern including large anomalies not only over the extratropical ocean but also over the polar land regions. The teleconnection pattern reverses sign with respect to the phases of SST in the extratropics (Fig. 10b). Overall, the patterns suggest the presence of zonally symmetric structures in the global atmosphere-ocean, interrupted by landocean thermal contrasts in the northern hemisphere.

Likewise, the ESST2 composites (Fig. 11) shows a circum-global wavetrain signal, that bear strong similarity, in the North Pacific region, to the "Shanghai -Kansas Express" pattern shown previously. This wavetrain appears to have shorter wavelength (approximately wavenumber 6) compared to its wintertime counterpart, i.e., the Pacific North American pattern (Wallace and Gutzler 1982). The signs of the wavetrain are 
reversed during the positive and negative phases of ESST2 (Fig.11b). The wavetrain seems to be associated with the fluctuations of the subtropical jets. Its linkage to the tropics is through an anomalous anticyclone in the subtropical western Pacific northeast of the Philippines. As suggested in the discussion of Fig.5a, this mode may be associated with the fluctuation of large-scale heat sources and sinks in the equatorial Indo-Pacific region.

\section{ASM Rainfall Predictability}

Interannual variability of the ASM can arise from internal dynamics and from changes in boundary conditions such as sea surface temperature (SST) and land surface conditions (Shukla 1984, Webser et al 1998). For seasonal-to-interannual predictions, the former constitutes the chaotic or unpredictable component, while the latter, the potentially predictable component of the ASM. The degree to which the ASM is controlled by each component determines the overall predictability of the ASM (Lau et al. 2000).

Up to now, season-to-interannual prediction of the ASM have depended on the existence of a physical relationship between ASM and ENSO (Rasmusson and Carpenter 1983, Webster et al. 1998 , Ju and Slingo 1995, Lau and Bua 1998, and others). However this relationship has undergone significant interdecadal variations. For example, the linear correlation of Indian summer monsoon rainfall and the Niño 3.4 SST has decreased dramatically in the last two decades (Kumar et al. 1999; Krishnamurthy and Goswami 1999, Chang and Li 2001). Previous studies and forecast experience have also shown that, while there may be some useful skill in forecasting ASM using ENSO-related indices, many extreme ASM droughts and floods occur without ENSO. By some 
estimate, more than half of the major monsoon rainfall extremes in the ASM occurred in non-ENSO years, suggesting that other factors must also contribute to the predictability (or lack thereof) of the ASM (Webster et al. 1998). Other predictors of ASM rainfall, such as regional SST, wintertime snow cover, springtime soil moisture and large scale circulation parameters have been used in conjunction with ENSO. However some of these predictors may be a function of the SST itself. Furthermore, many previous predictability studies tend to focus on the impact of the ASM by ENSO and paid relatively little attention to the possible contribution by possible intrinsic variability of SST outside the tropical Pacific.

Discussions in the previous sections suggest there may be natural variability in the extratropical oceans that are distinct from ENSO, but can profoundly affect climate of East Asia and North America during the boreal summer. This raises the possibility that regional SST variability outside the tropical Pacific, even though relatively smaller in variance compared to ENSO, may provide additional information that will improve regional ASM predictions. Recently, Lau et al (2001) and Shen et al (2001) have developed a new Canonical Ensemble Correlation (CEC) prediction and diagnostic procedure that utilizes, among others, information from various basin scale SST modes to maximize regional rainfall prediction skills. In the following, we shall illustration the application of the CEC to evaluate the potential predictability of the ASM rainfall due to the various ocean basins. To capture SST signals contained in the various ocean basins, the world ocean is divided into five non-overlapping sectors: the tropical Pacific, the North Pacific, the tropical Atlantic, the North Atlantic and the Indian Ocean, with the tropical oceans defined within the latitudes of $30^{\circ} \mathrm{S}$ and $30^{\circ} \mathrm{N}$, and the north oceans north 
of $30^{\circ} \mathrm{N}$. The southern oceans have not been included in the present analysis. A canonical correlation prediction model is developed for each of the ocean basin and used to predict the same target ASM rainfall field, i.e., $2 \times 2.5$ degree CMAP rainfall over the Asian-Australia land domain (see Fig. 12 and 13). Up to six canonical variables are used to depict the intrinsic variability within each ocean basin. Separate forecasts are made from each ocean basin, and then combined into an ensemble forecast using various ensemble averaging strategies including those used in super-ensemble predictions (Krishnamurti et al. 2000). For illustration, here we use the maximum skill ensemble, in which the best forecast among the five ocean-basin forecasts is always chosen at a particular grid point.

The results shown in the following are based on 49 years (1950-1998) of seasonal mean ASM rainfall and SST. To increase data sample, a bootstrapping method is used in which a forecast for a particular year is carried out by taking out that year from the training period ( 48 years), and all the statistics are recomputed based on the new 48 years. To quantify prediction skill, we chose a three category hit score (HS). The observed rainfall is ranked in terms of three equal-size categories, above-normal, normal and below-normal at each grid point, according to the magnitude of the rainfall anomaly. The HS is defined as the percentage of the number of hits in anyone category to the total number of forecasts. Hence, a hit score of $33.3 \%$ will be considered no skill. For the sample we used, the $5 \%$ and $1 \%$ confidence level corresponds respectively to a $\mathrm{HS}$ of $45 \%$ and $50 \%$ respectively.

The CEC is a prediction scheme that can be used for empirical forecasting ASM seasonal rainfall anomalies with different lead times, $\Delta t .>0$. Here, we define the potential 
predictability as the HS obtained when $\Delta t=0$, i.e., when there is perfect knowledge of the predictor (SST) field. Using the above procedure, the potential predictability is obtained as the climatological HS computed based on 49 forecasts. To put the ASM rainfall variability and predictability in a broader context, we show results for the entire AsianAustralian monsoon (AAM) region. Fig. 12 shows the potential predictability, or climatological HS from each model forecasts (with zero lag) based on SST variability in each ocean basin and the overall potential predictability based on the CEC. For the individual ocean basins, it can be seen that the tropical Pacific and the Indian Ocean provide the largest contribution to potential predictability ( $>45 \%)$ to the ASM, mostly over Indonesia and Australia. The North Pacific, the tropical Atlantic and the North Atlantic also contribute to potential predictability in various regions, but in decreasing order of importance. Obviously, there is a large degree of spatial variability of potential predictability attributed to SST variability in the different ocean basins. For example, the tropical Pacific affects most strongly eastern Australia, while the Indian Ocean has the dominant impact on western Australia and southwestern Indonesia. Potential predictability over India and East Asia is very low based on SST variability of individual ocean basins only, including the tropical Pacific. Remarkably, using the CEC technique, in which SST variability associated with intrinsic modes in each ocean basin are optimized, the potential predictability over the AAM region as a whole is substantially enhanced. The potential predictability is much increased over Australia and Indonesia, and also over central East Asia and central Asia, and regions in southern and eastern India. 
Fig. 13 shows the distribution of sources of potential predictability for the AAM region. The color shading indicates the ocean basin which gives the highest mean HS (based on 49 forecasts) for that location. Although the following discussion is focused on JJA, all four seasons are shown in Fig. 13 for comparison. Overall, the SST in the tropical Pacific stands out as the most important source of potential predictability, as evidenced in the large proportion of areas shaded red for all seasons. This result is not surprising, confirming the notion that El Niño is the primary contributor to monsoon rainfall variability in the AAM region. In some regions, such as central and northern India, the impact from the tropical Pacific (El Niño) alone, while ranked the best, may still be subcritical, in the sense of yielding a significant HS score based on tropical Pacific SST alone. During JJA, the source of potential predictability in western Australia and western rim of Indonesia appear to be from the Indian Ocean (colored purple). This means that the impact of the Indian Ocean SST anomalies trumps that from the El Niño in the above regions. Over southern Japan and coastal region of China, the importance of the SST in the North Pacific (colored blue) is noted. Indeed, in the northern subtropics and extratropics, much of the potential predictability can be attributed to North Pacific SST, especially in MAM and SON. During DJF, the North Atlantic (colored green) appears to gain influence over the extratropical latitudes.

In summary, CEC provides a prediction and diagnostic tool whereby potential predictability of ASM rainfall arising from both regional and remote influences can be estimated. Most important, via CEC, the source of potential predictability can be easily identified and traced to specific canonical climate modes (not shown here). Therefore CEC can be very useful in unraveling the physical mechanisms and the sources for ASM 
predictability. It also provides a common framework in which ASM predictions from general circulation models and from empirical schemes can be quantitatively compared.

\section{Conclusions}

In this Chapter, we have presented results of the latest research on the global teleconnection associated with interannual variability of the ASM and its possible implications on potential predictability of ASM. We have pointed out differences in basic dynamics in interannual variability between SAM and EAM. One of the main consequences in the fundamental difference in dynamics between SAM and EAM is that the interannual variability in the EAM is underpinned by more pronounced teleconnection patterns. The dominant teleconnection patterns associated with summertime rainfall anomalies over EAM and North America project strongly, respectively on two intrinsic SST modes in the North Pacific and North Atlantic. The first mode (Mode-1) features extensive body of cold (warm) water along $40^{\circ} \mathrm{N}$, stretching across the entire North Pacific and Atlantic, lying underneath zonally oriented low (high) $500 \mathrm{hPa}$ height anomalies. Over the East Asia/western Pacific region, Mode-1 resembles the characteristic structure of associated with the fluctuation of the East Asian jetstream. Over North America, it projects on a regional circulation pattern that regulates moisture transport from the Gulf coast to the US Midwest. Mode-1 appears to be related to the variability of the boreal summer subtropical jetstream linking warm/dry or cool/wet summertime climate of Japan and South Korea to anomalies of the same sign over western Canada, the northern Great Plains and the US Midwest. 
Mode-2 depicts a circum-global wavetrain (approximate wavenumber 6) connecting Eurasia via the North Pacific to North America and the North Atlantic. The wavetrain is linked to a pronounced low-level anticyclone over the subtropical western Pacific, and dominant heat source/sink variability in the Indo-Pacific region. Mode-2 is likely to be associated with Rossby wave dispersion derived from fluctuation of anomalous heat sources and sinks in the western Pacific and Indian Ocean, and because of its insensitivity to the exact location of the forcing, it is also consistent with marginally unstable summertime basic state found in previous studies (Nitta 1987; Lau and Peng 1992). As such, Mode- 2 will be affected by the Mode- 1 which is likely to alter the climatological monsoon basic flow.

Using a canonical ensemble correlation (CEC) prediction scheme, the potential predictability of the ASM derived from intrinsic SST variability in the major world ocean basins has been assessed. It is confirmed that the tropical Pacific is the major source of predictability in the Asian-Australia monsoon region, especially over Indonesia and eastern Australia. However, there are monsoon sub-regions, where the major source of predictability is derived from ocean basins outside the tropical Pacific. Predictability is low over the India subcontinent from all individual ocean basins, including the tropical Pacific. In JJA, the Indian Ocean contribution to rainfall variability in the western Australia, and the southwestern Indonesia is stronger than those from the tropical Pacific. The North Pacific contributes more to rainfall variability over southern Japan and northern China in boreal summer and fall. Most important, by optimizing contributions from the different ocean basins, the CFC prediction yields overall improvement in potential predictability in all ASM regions, including the Indian subcontinent. 


\section{Reference}

Anamalai, H. and J. M. Slingo, 2001: Active/Break cycles: Diagnosis of the intraseasonal variability of the Asian Summer monsoon. Climate Dynamics ( in press).

Chang, C. P. and T. Li, 2000: A theory of the tropospheric biennial oscillation. J. Atmos. Sci., 57, 2209-2224.

Chung, C., and S. Nigam ,2000: Asian summer monsoon-ENSO feedback on the CaneZebiak model ENSO. J. Climate, 12, 2787-2807.

Gill, A. E., 1980: Some simple solutions of heat-induced tropical circulation. Quart. J. Roy. Meteor. Soc., 106, 447-462.

Goswami, B. N., V. Krinshamurthy and H. Annamalai, 1999: A broad scale circulation index for the interannual variability of the Indian summer monsoon. Quart. J. Roy. Meteor. Soc., 125, 611-634.

Hoerling M..P., J. W. Hurrell, and T. Xu, 2001: Tropical origin for recent North Atlantic climate change. Science, $292,90-92$.

Huang, R.-H., and F. Y. Sun, 1992: Impacts of the tropical western Pacific on the East Asian summer monsoon. J. Meteor. Soc. Japan, 70, 243-256.

Ju, J. and J. Slingo, 1995: The Asian summer monsoon and ENSO. Quart. J. Roy. Meteor. Soc., 121, 1133-1168.

Kim, K. M., and K. M., Lau , 2000: Dynamics of monsoon-induced biennial variability in ENSO. Geophys. Res. Letter., 28, 315-318.

Kirtman, B. P., and J. Shukla , 2000: Influence of the Indian summer monsoon on ENSO. Quart. J. Roy. Meteor. Soc., 126, 213-239. 
Krishnamurthy, V., and B. N. Goswami, 2000: Indian Monsoon-ENSO relationship on interdecadal timescale. J. Climate, 13, 579-595.

Krishnamurti T.N., C. M., Kishtawal, D. W., Shin , C. E., Williford, 2000: Improving tropical precipitation forecasts from a multianalysis superensemble. J. Climate, 13, $4217-4227$

Kumar, K. Krishna, Balaji Rajagopalan, Mark A. Cane, 1999: On the weakening relationship between the Indian Monsoon and ENSO. Science, 284, 2156-2159.

Lau K. M., K. M. Kim and S. Shen, 2001: : Statistical mining of potential predictability of seasonal precipitation forecast. Geophys. Res. Letters (submitted).

Lau, K. M, 1992: East Asian summer monsoon variability and climate teleconnection. $J$. Meteor. Soc. Japan, 70, 211-242.

Lau, K. M. and H. Lim, 1982: Thermally induced motions in an equatorial b-plane: Hadley and Walker circulation during the winter monsoon. Mon. Wea. Rev., 110, 336-353.

Lau, K. M. and H. Weng, 2000: Teleconnection linking summertime rainfall variability over North America and East Asia. CLIVAR Exchanges, 5, 18-20.

Lau, K. M. and H. T. Wu,, 2001: Intrinsic modes of coupled rainfall/SST variability for the Asian summer monsoon: a re-assessment of monsoon-ENSO relationship. $J$. Climate, 14, 2880-2895.

Lau, K. M. and H. Weng, 2000: Remote forcing of US summertime droughts and floods by the Asian monsoon? GEWEX News, 10, May Issue, 5-6. 
Lau, K. M. and H. Weng, 2001: Coherent modes of global SST and summer rainfall over China: an assessment of the regional impacts of the 1997-98 El Nino. J. Climate, 14, 1294-1308.

Lau, K. M., and H. T. Wu, 1999: An Assessment of the impact of the 1997-98 El Niño on the Asian-Australian monsoon. Geophys. Res. Lett., 26, 1747-1750.

Lau, K. M., K. M. Kim, and S. Yang, 2000: Dynamical and Boundary Forcing Characteristics of regional components of the Asian summer monsoon. J. Climate, 13, 2461-2482.

Lau, K.-M. and L. Peng, 1992: Dynamics of atmospheric teleconnections during the northern summer. J. Climate., 5, 140-158.

Lau, K-M., and W. Bua, 1998: Mechanism of monsoon-Southern Oscillation coupling: insights from GCM experiments. Climate Dynamics, 14, 759-779.

Lau, N. C., and M. J. Nath, 2000: Impact of ENSO on the variability of the AsianAustraalian monsoons as simulated in GCM experiments. J. Climate, 13, 42874309.

Lau, N. C., and M. J: Nath, 1996: The role of "atmospheric bridge" in linking tropical Pacific ENSO events to extratropical SST anomalies. J. Climate, 9, 2036-2057.

Lau, N. C., and M. J. Nath, 2001: Impact of ENSO on SST variability in the North Pacific and North Atlantic: seasonal dependence and role of extratropical air-sea interaction. J. Climate., 14, 2846-2866.

Meehl, G. A., 1997: The South Asian monsoon and the tropospheric biennial oscillation. J. Climate., 10, 1921-1943. 
Meehl, G. A., and J. Arblaster, 1998: The Asian-Australian monsoon and El NinoSouthern Oscillation in the NCAR climate system model. J. Climate. 11, 13561385.

Nitta, T., 1987: Convective activities in the tropical western Pacific and their impact on the northern hemisphere summer circulation. J. Meteor. Soc. Japan, 41, 373-390.

Rasmusson, E. M, and T. H. Carpenter, 1983: The relationship between eastern equatorial Pacific sea surface temperature and rainfall over India and Sri Lanka. Mon. Wea. Rev., 111, 517-528.

Sardesmukh, P. and B. Hoskins, 1988: The generation of global rotational flow by steady idealized tropical divergence, J. Atmos. Sci. 45, 1228-1251.

Shen S.S. K. M. Lau, K. M. Kim 2001: A canonical ensemble correlation prediction model for seasonal precipitation anomalies. NASA Tech Memo, XXXXX.

Shen, X., and M. Kimoto, 1999: Influence of El Nino on the 1997 Indian summer monsoon. J. Meteor. Soc. Japan, 77, 1023-1037.

Shukla. J., 1984: Predictability of time averages, Part II: The influence of boundary focing. Problems and prospects in long and medium range weather forecasting. Editors: D. M. Burridge and E. Kallen, Springer-Verlag, pp. 115-206.

Ting, M. and H. Wang, 1997: Summertime U. S. precipitation variability and its relation to Pacific sea surface temperature. J. Climate, 10, 1853-1873.

Wallace, J. M., and D. Gutzler, 1981: Teleconnections in the geopotential height field during the northern hemisphere winter. Mon. Wea. Rev., 109, 784-812. 
Wang, B., and Z. Fan, 1999: Choice of South Asian summer monsoon indices. Bull. Am. Meteor. Soc., 80, 629-638.

Wang, B., R. Wu and K. M. Lau, 2001: Contrasting interannual variations between the Indian and the western North Pacific summer monsoon. J. Climate (in press).

Webster, P. J., V. O. Magana, T. N. Palmer, J. Shukla, R. A. Tomas,, M. Yanai, and T. Yasunari, 1998: Monsoon: Processes, predictability, and the prospects for prediction. J. Geophys. Res., 103, 14,451-14,510.

Yasunari, T., and Y. Seki, 1992: Role of the Asian monsoon on the interannual variability of the global climate system. J. Meteor. Soc. Japan, 70, 177-189. 


\section{Figure Captions}

Fig. 1 Linear regression of South Asia Monsoon index, RM1, against a) rainfall anomalies (mm/day), b) $850 \mathrm{hPa}$ wind $\left(\mathrm{ms}^{-1}\right)$, and c) $200 \mathrm{hPa}$ wind (ms-'). Areas with correlation exceeding the $95 \%$ confidence level are shaded yellow in b) and c).

Fig. 2. Same as in Fig. 1, except for the East Asian Monsoon index, RM2.

Fig. 3. Correlation map showing the teleconnection pattern of the $300 \mathrm{hPa}$ geopotential height associated with a) RM1 and b) RM2. Units are non-dimensional with a contour interval of 0.1 .

Fig. 4. Linear regressions of principal component of Mode-1 North America summertime rainfall, against a) global precipitation $\left(\mathrm{mm} \mathrm{day}^{-1}\right)$ and $850 \mathrm{hPa}$ winds $\left(\mathrm{ms}^{-1}\right)$, and b) sea surface temperature $\left({ }^{\circ} \mathrm{C}\right)$.

Fig. 5. Same as in Fig. 4, except for Mode-2.

Fig. 6. Lnear regression of Mode-1 against a) global $500 \mathrm{hPa}$ geopotential height (dm) and $850 \mathrm{hPa}$ winds $\left(\mathrm{ms}^{-1}\right)$, and b) $200 \mathrm{hPa}$ divergent circulation $\left(\mathrm{ms}^{-1}\right)$.

Fig. 7. Same as in Fig. 6, except for Mode-2.

Fig. 8. Eigenvector of JJA seasonal SST in the North Pacific and North Atlantic for a) first mode and b) second mode, and c) corresponding principal components. Multiplication of contour values and time coefficients yield units in ${ }^{\circ} \mathrm{C}$. 
Fig. 9. Lagged correlation of ESST1 and ESST2 principal components with monthly SST in Niño-3.4 region for 12 months before and after current summer season . Confidence levels of $1 \%$ and $5 \%$ are marked.

Fig. 10. Composites of $500 \mathrm{hPa}$ geopotential height $(\mathrm{dm})$ and $850 \mathrm{hPa}$ winds $\left(\mathrm{ms}^{-1}\right)$ with ESST1 for a) positive phase of ESST1- warm North Pacific, and b) negative phase - cold North Pacific.

Fig. 11. Same as in Fig. 10, except for ESST2.

Fig. 12 Potential Predictability (see text for definition) of ASM monsoon seasonal rainfall based on SST variability in the various ocean basins, a) tropical Pacific, b) North Pacific, c) tropical Atlantic, d) North Atlantic, e) Indian Ocean and f) CEC.

Fig. 13 Source function showing distribution of most influential (based on anomaly correlations) ocean basin on predictability in ASM region for a) DJF, b) MAM, c) JJA and d) SON. 

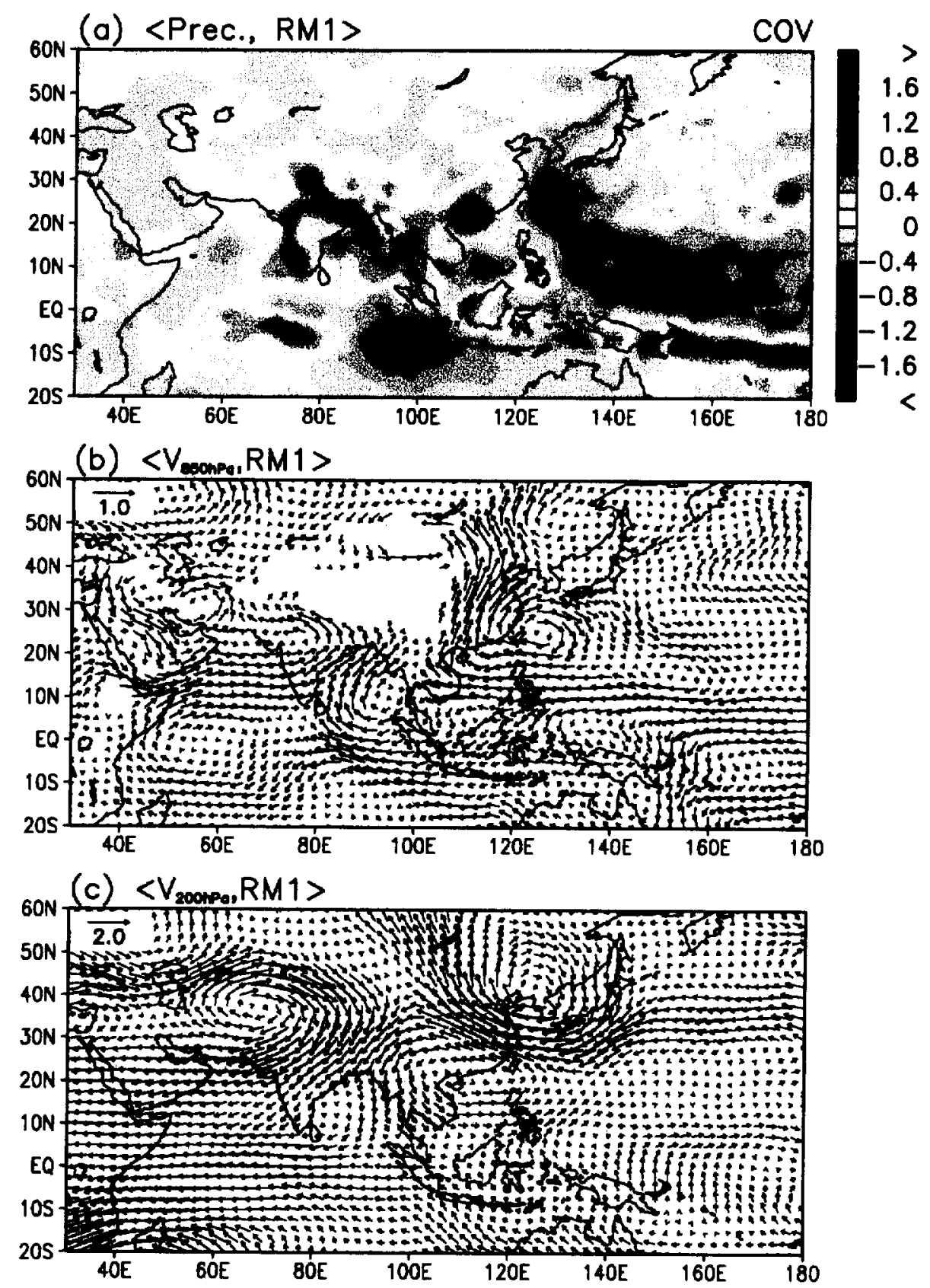

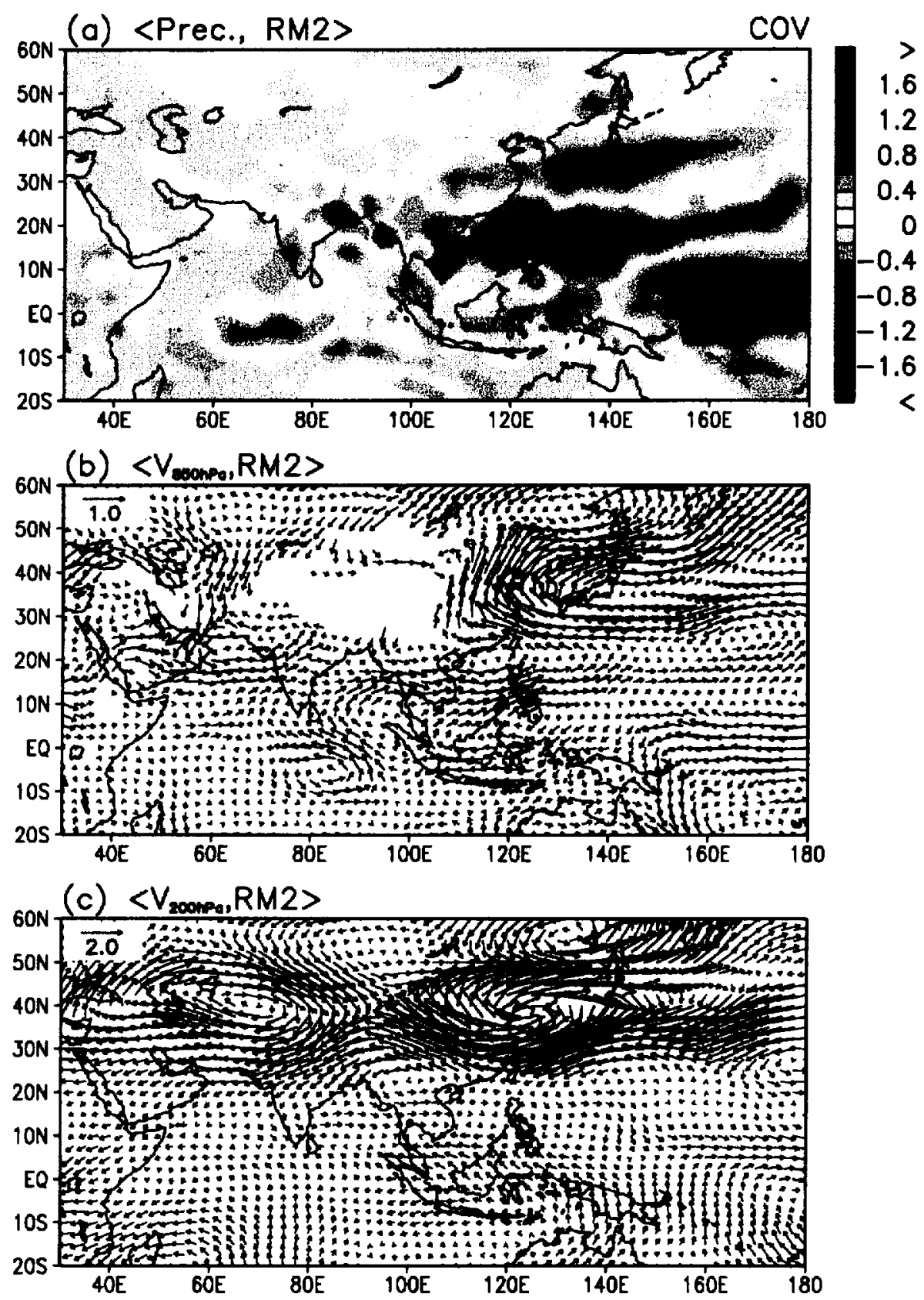

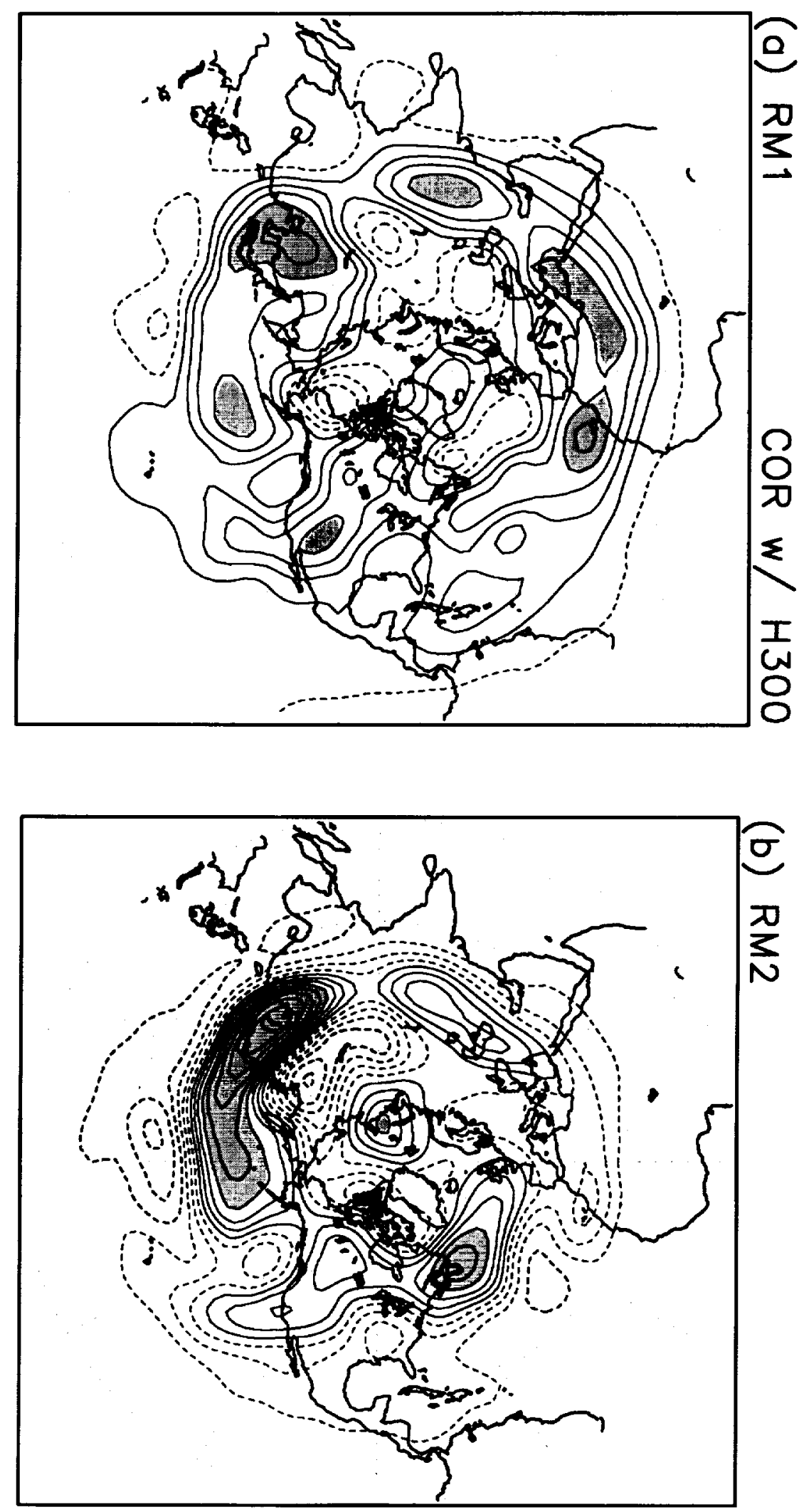

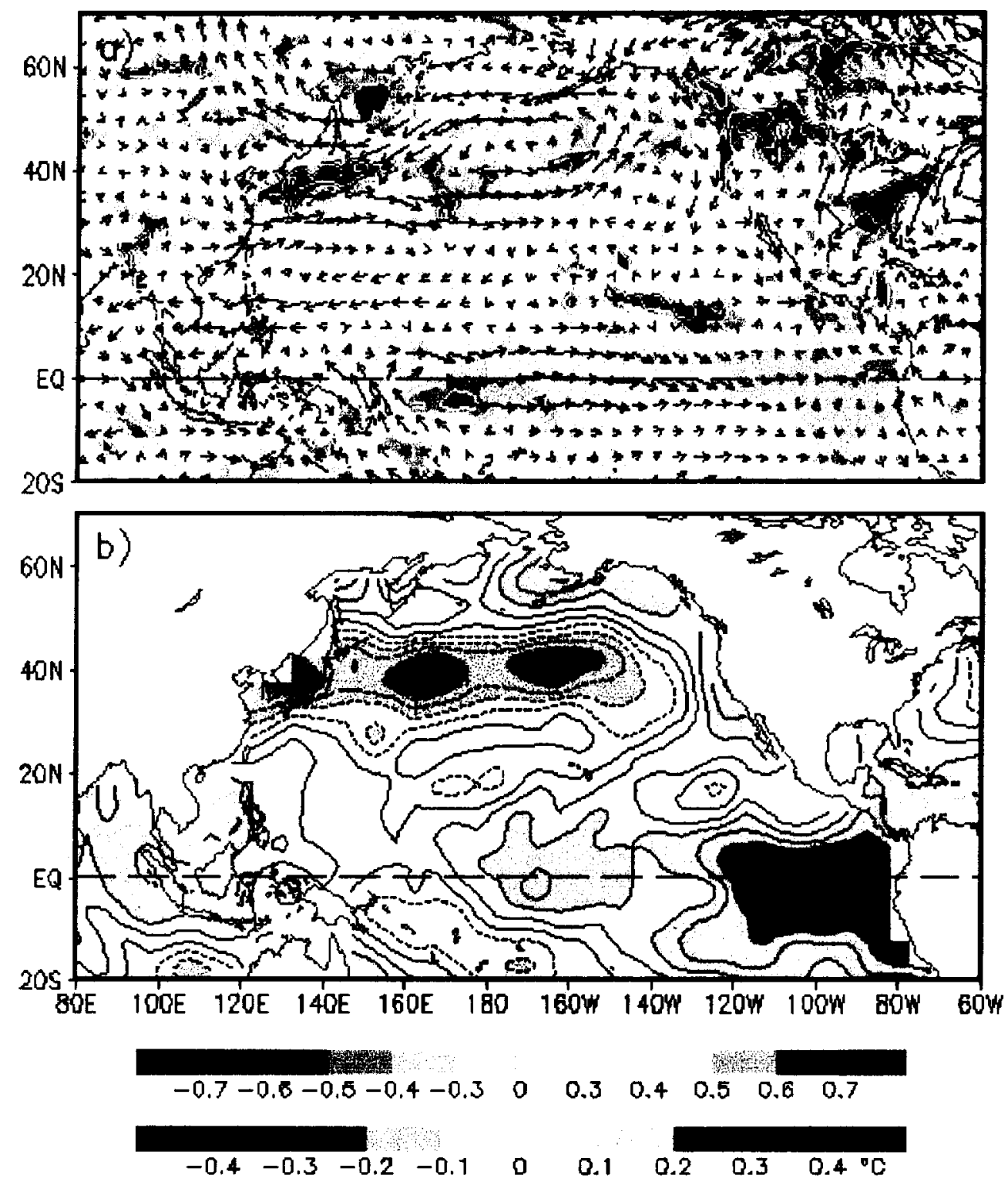

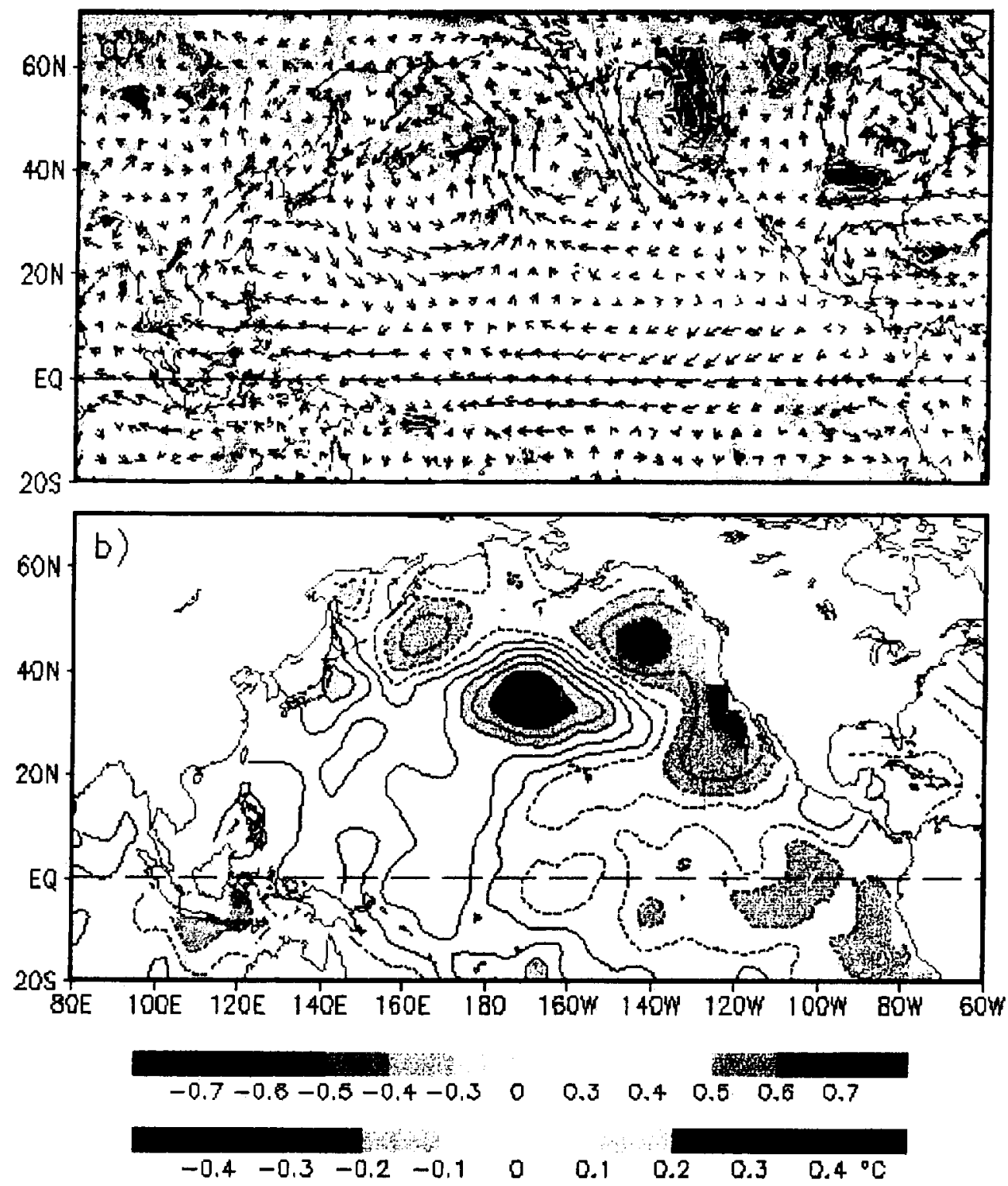

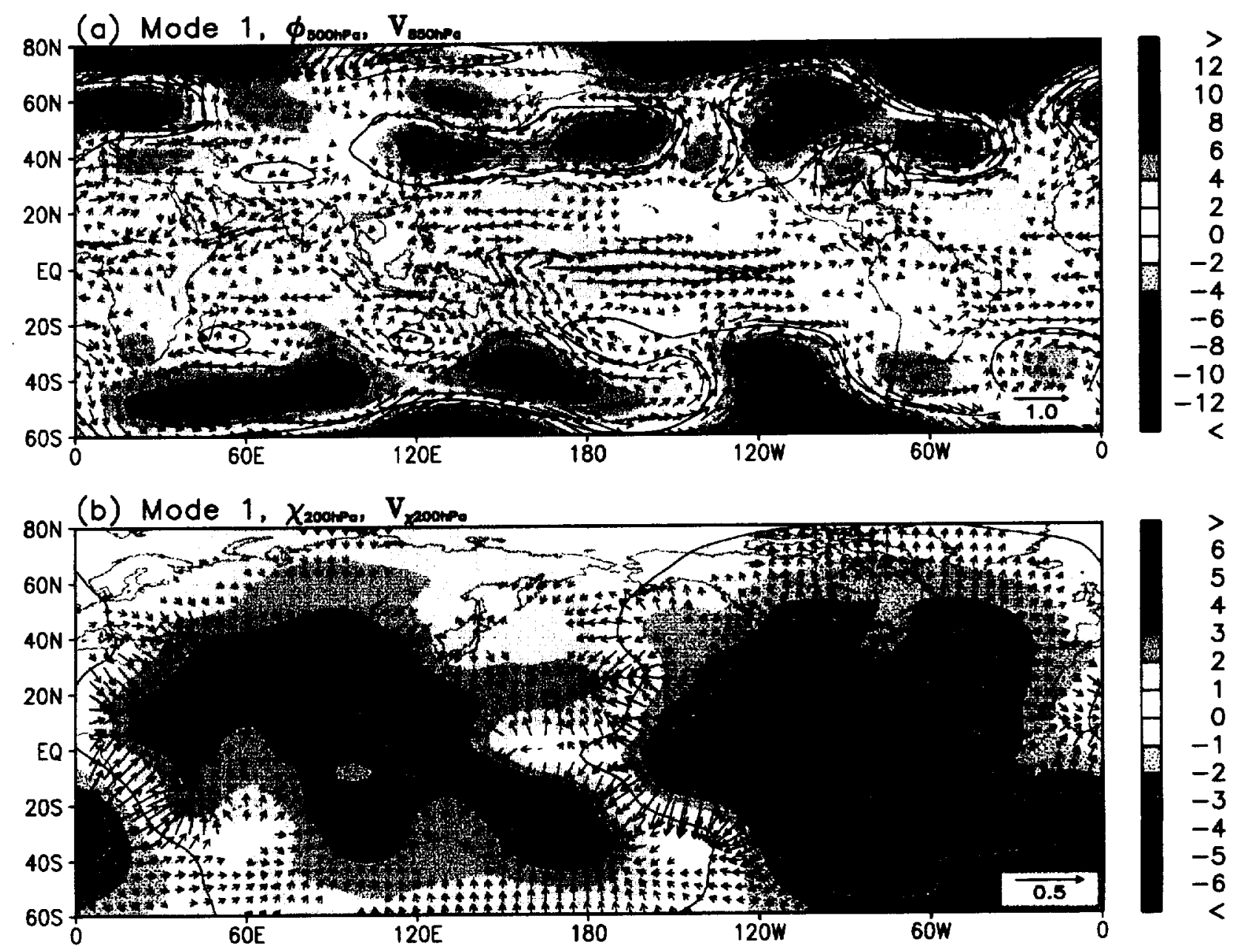

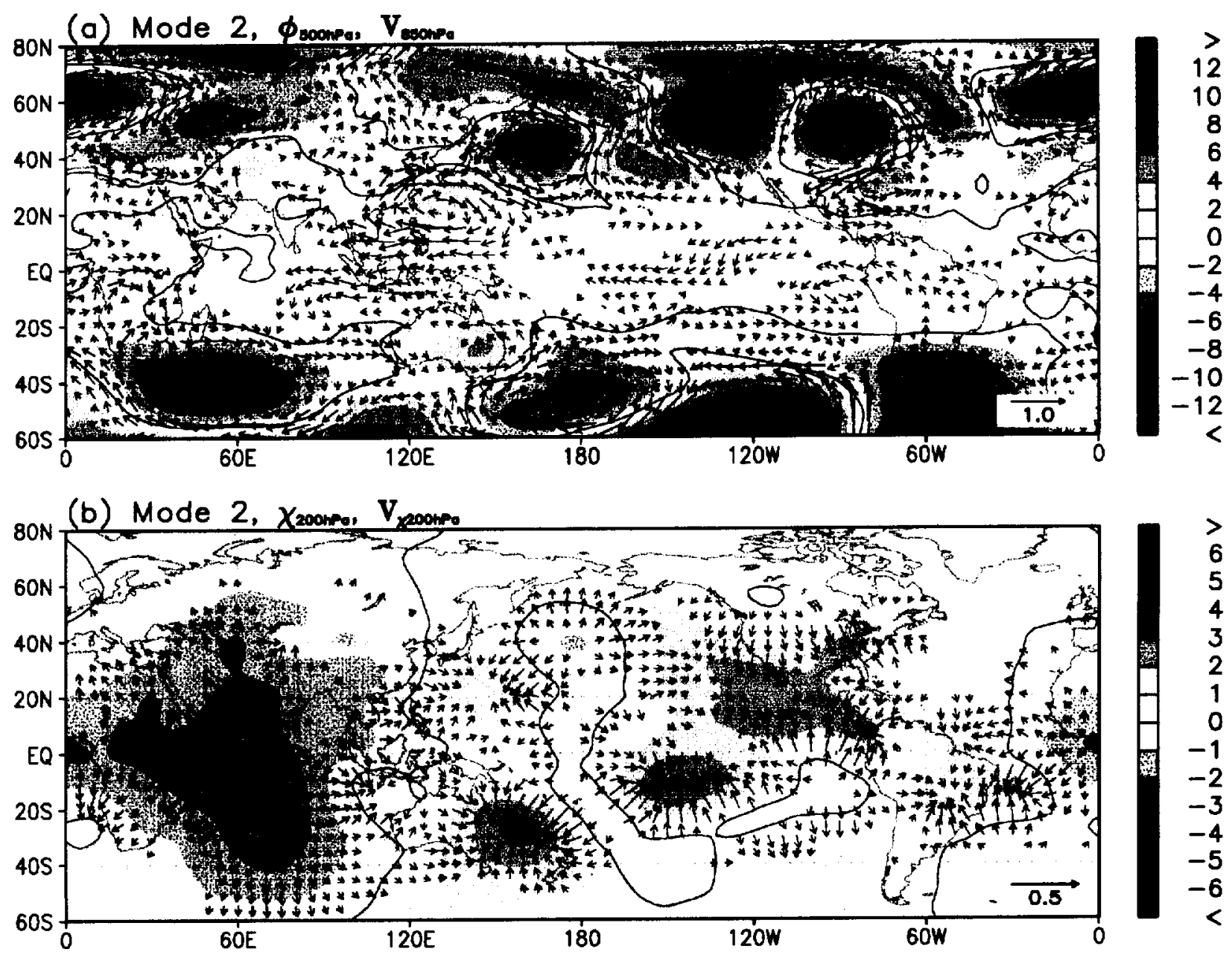
(a) Mode-1

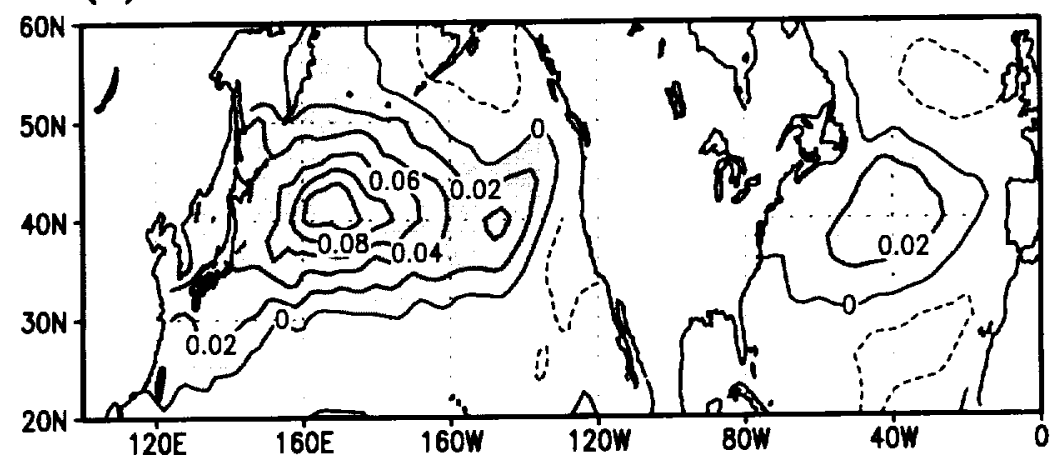

(b) Mode-2

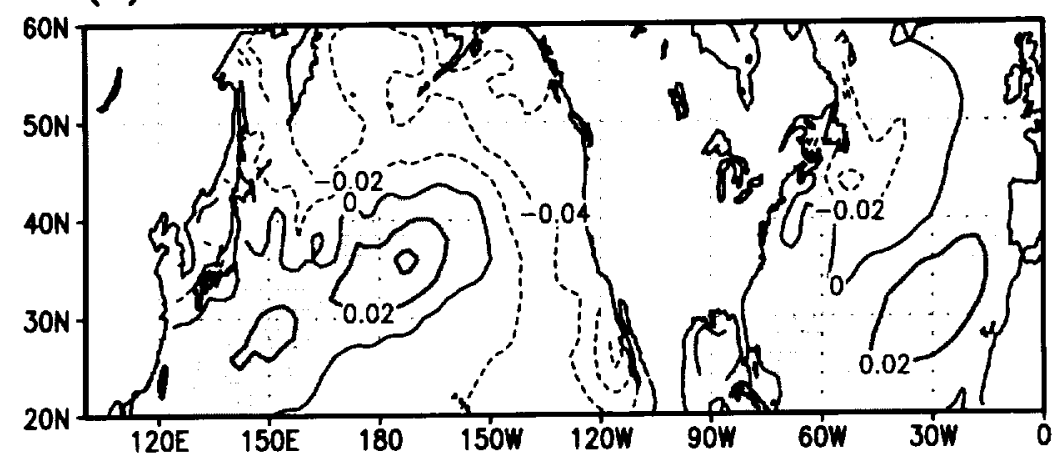

(c) Time coefficients

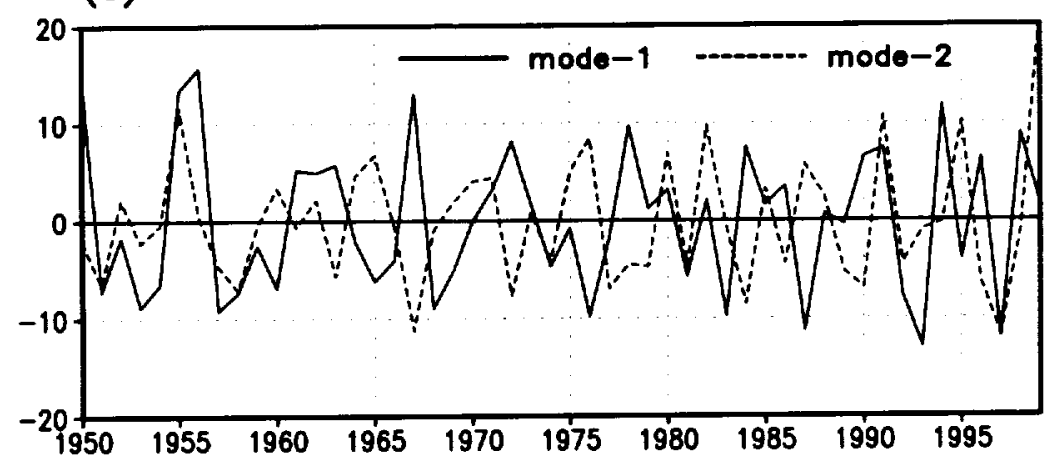




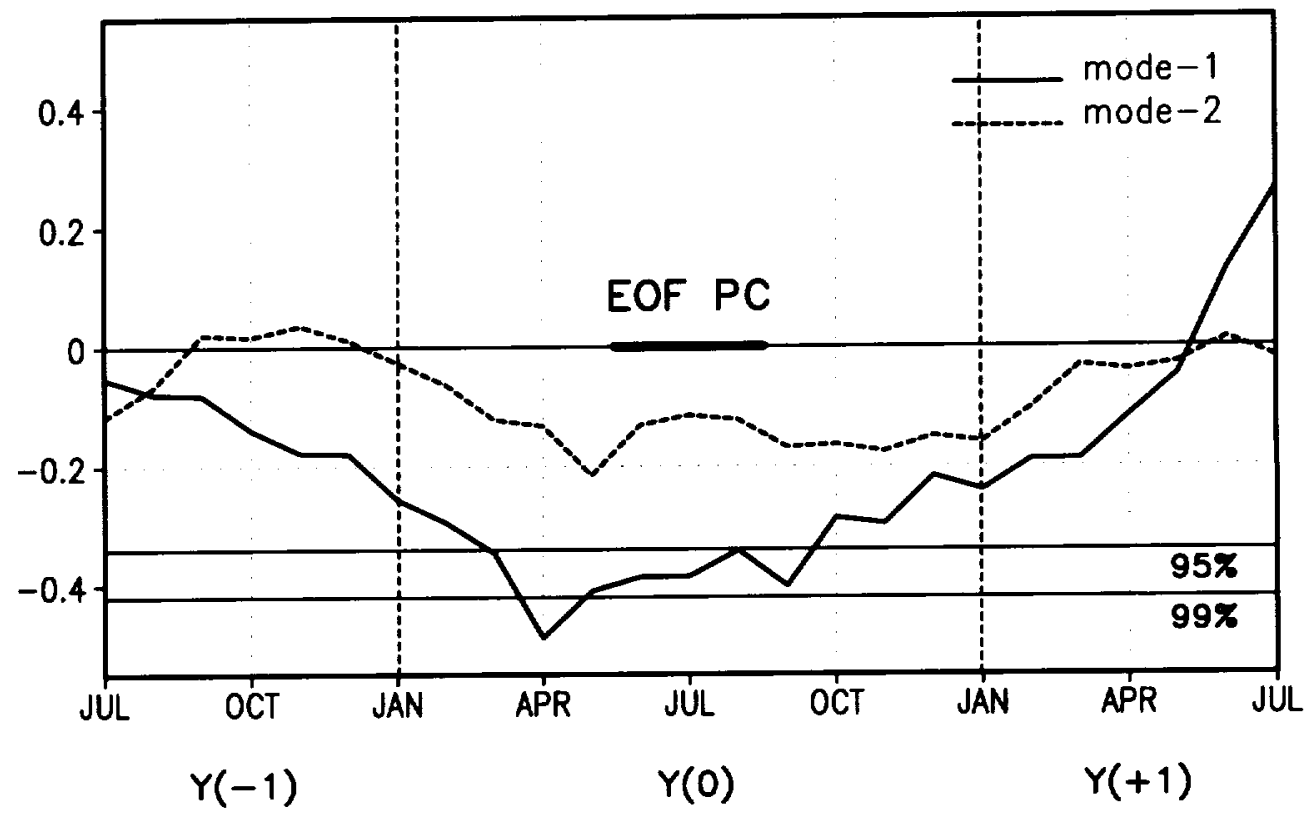

Fig 
(a) Maximum phase

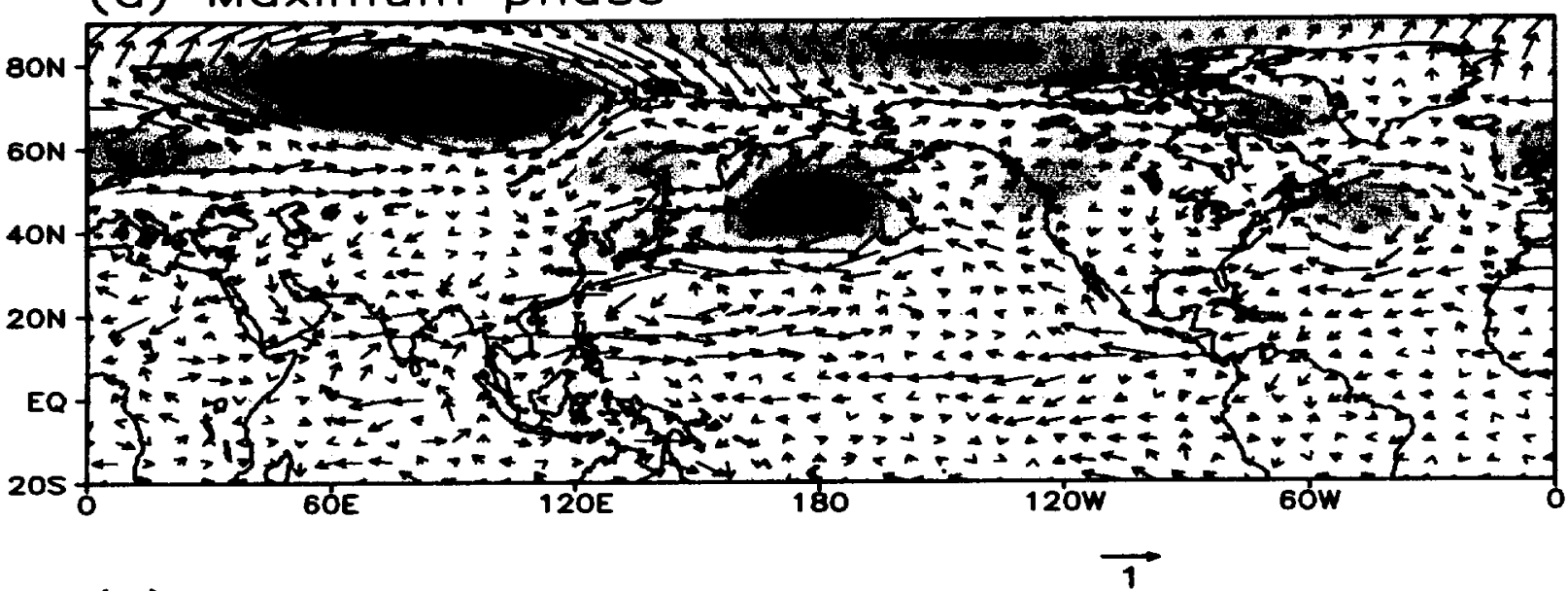

(b) Minimum phase

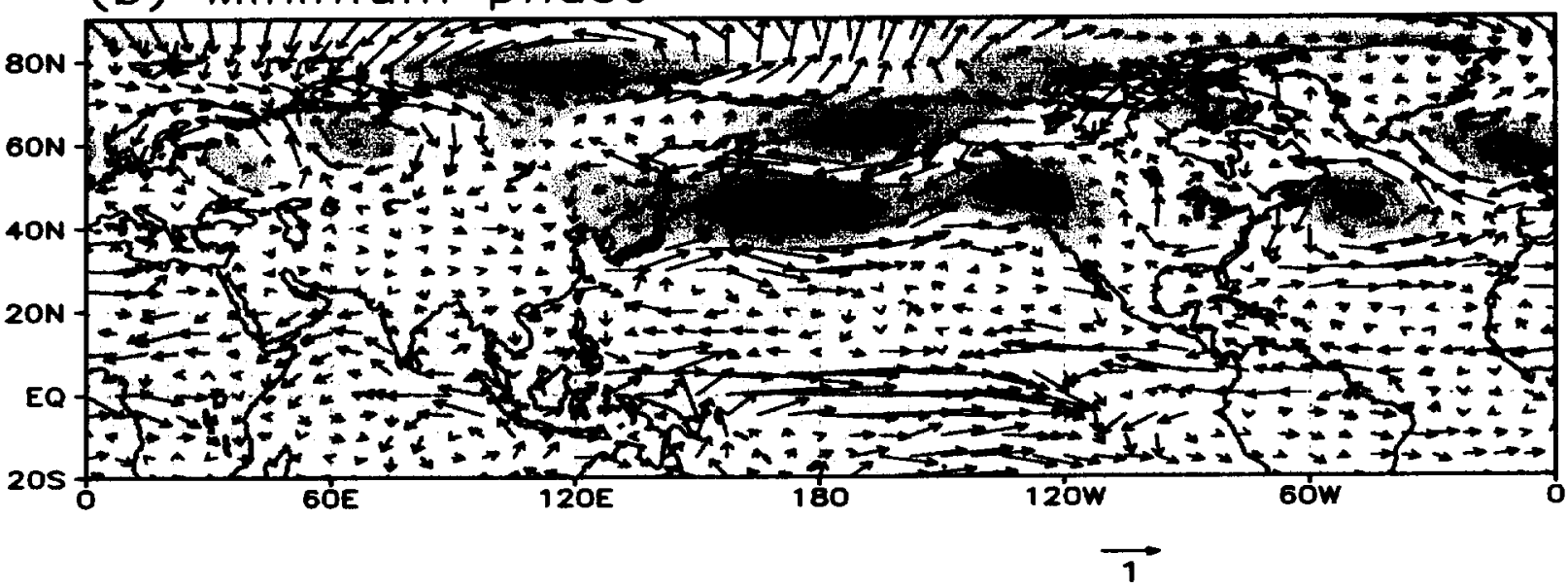

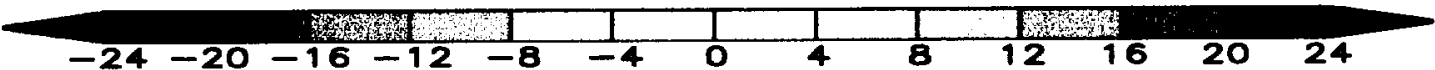


(a) Maximum phase

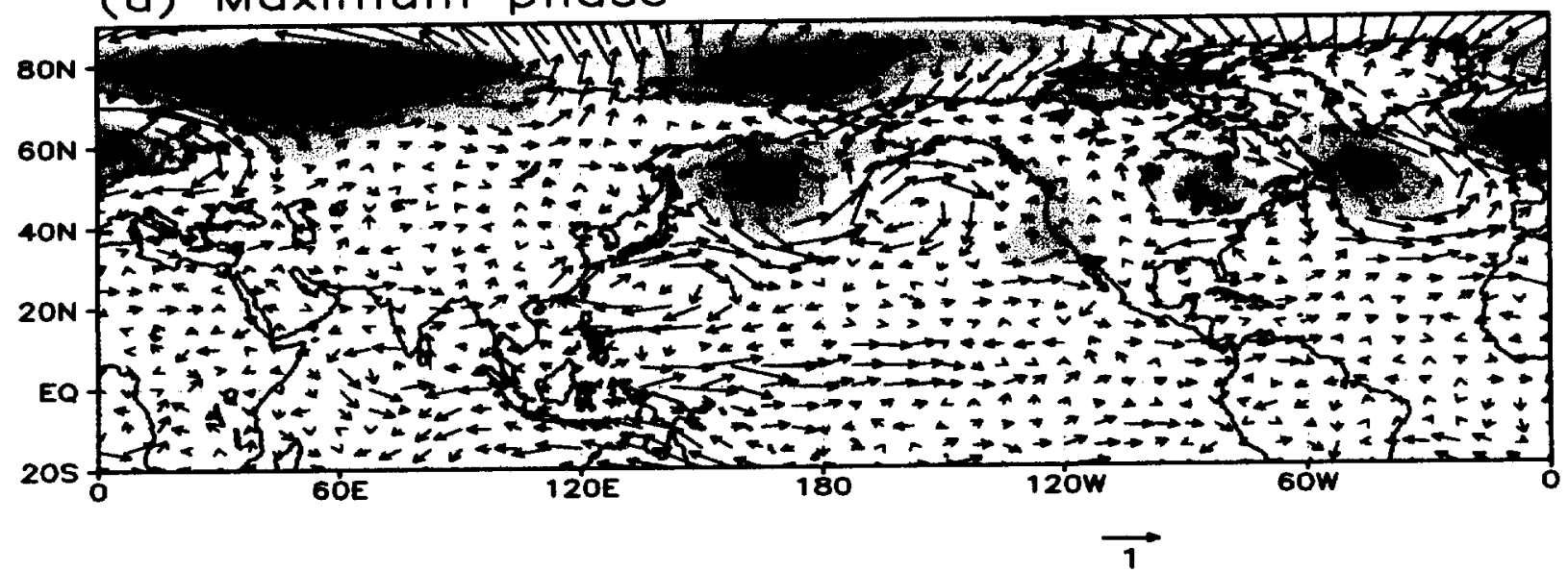

(b) Minimum phase
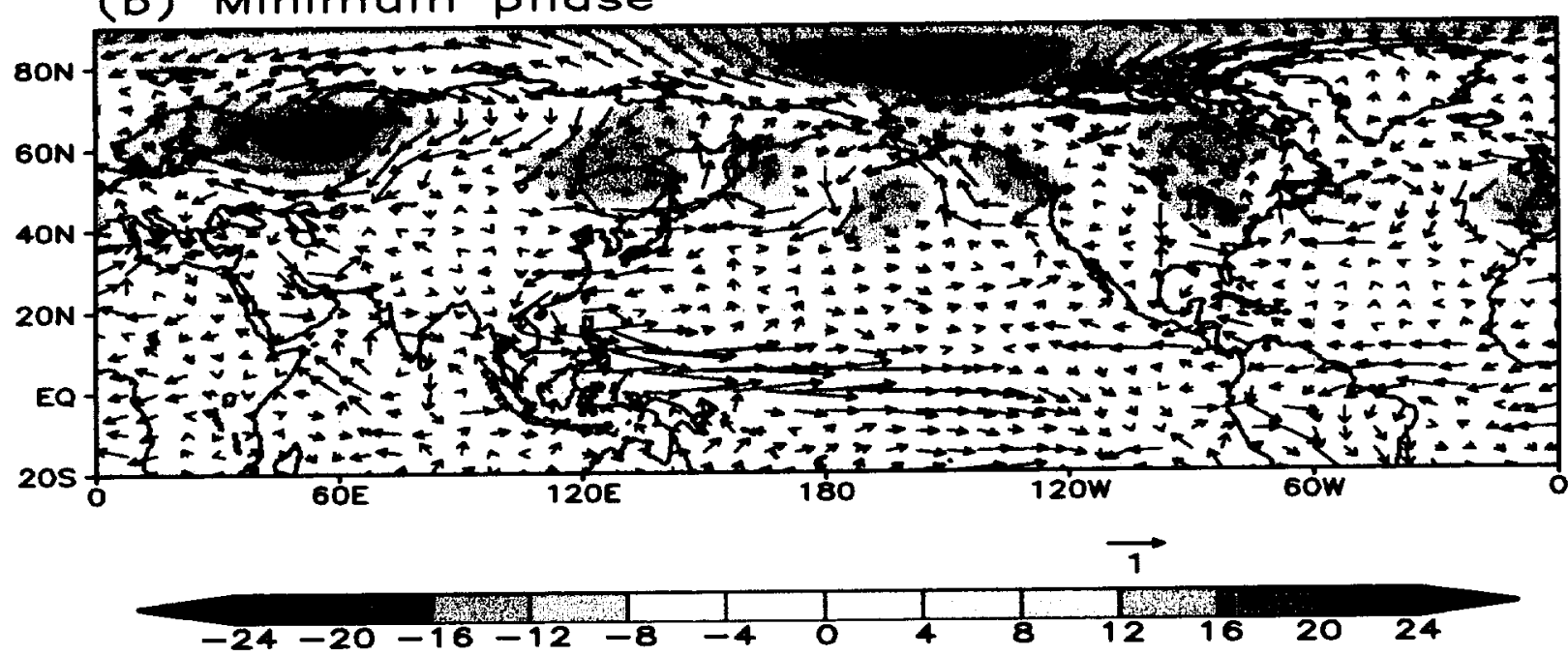
JJA : Percentage of the Hit (\%)

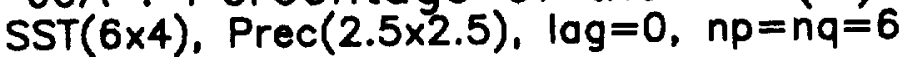
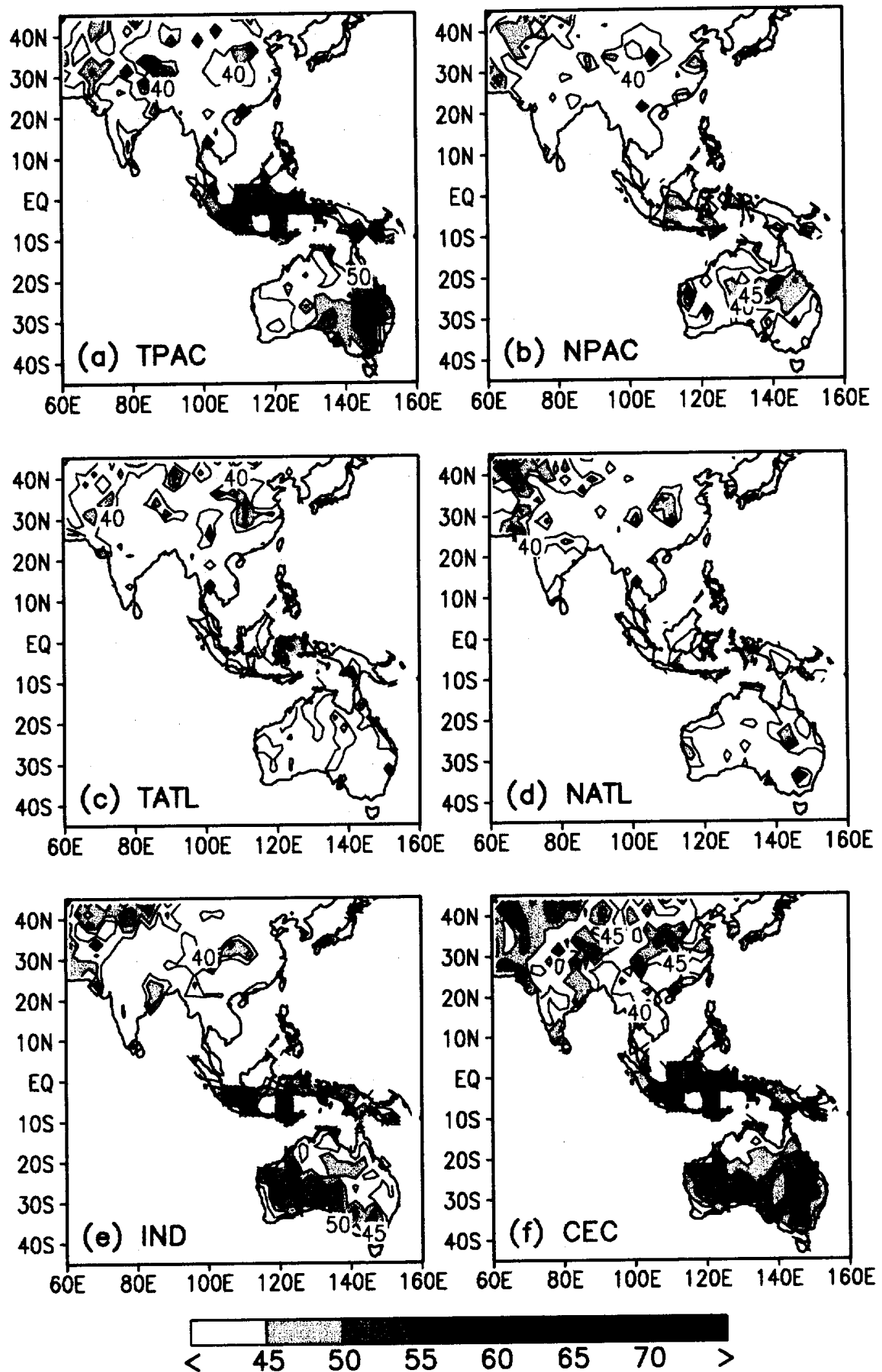
Max. Temporal Correlation

$\operatorname{SST}(6 \times 4), \operatorname{Prec}(2.5 \times 2.5), \log =0, n p=n q=6$
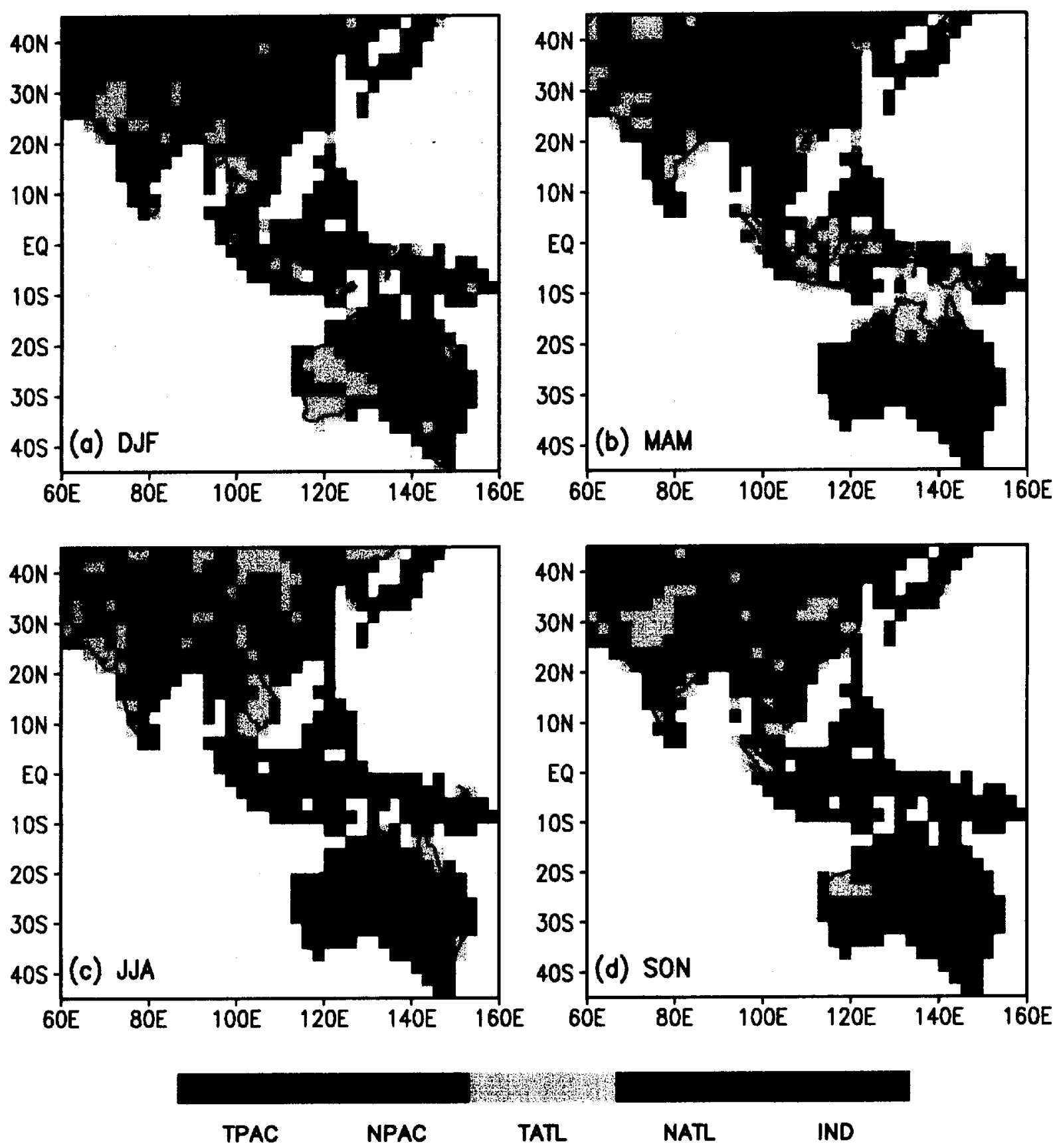